Reprod. Nutr. Dévelop., 1985, 25 (1 B), 333-334.

\title{
Métabolisme rénal du palmitate au cours de la période périnatale chez le rat
}

\author{
Evelyne DELAVAL, Nicole FREUND, S. ANDRIAMANANTSARA, J. P. GELOSO \\ Laboratoire de Différenciation fonctionnelle, Université Paris 7, \\ 75251 Paris Cedex 05.
}

La naissance s'accompagne, chez le Rat, d'un brusque changement de l'environnement nutritionnel. Pendant la vie fœtale, le métabolisme oxydatif est assuré essentiellement par le glucose (d'origine maternelle) et le lactate (d'origine placentaire) tandis qu'à la naissance et dans les heures qui suivent, le nouveau-né se trouve confronté à une alimentation lactée riche en lipides et pauvre en glucides. Le rein doit donc très rapidement acquérir la capacité $d^{\prime}$ oxyder les acides gras pour assurer ses besoins énergétiques.

Des études réalisées in vitro (Freund et al., 1984) ont montré que l'oxydation du palmitate est faible pendant la vie foetale, qu'elle augmente à la naissance pour atteindre à 5 jours post partum (p.p.) une valeur 3 fois plus élevée que celle mesurée en fin de gestation. L'un des facteurs susceptibles de limiter l'oxydation des acides gras pourrait être l'activité de la Palmitoyl-Carnitine-Transférase (P.C.T.1), enzyme permettant le transfert des acides gras à longue chaîne du cytosol au sein de la matrice mitochondriale. En effet, l'activité de la P.C.T.1, mesurée à partir d'homogénats de reins, selon la technique décrite par McGarry et al. (1978), est faible dans le rein de fœetus en fin de gestation, elle augmente rapidement à la naissance $(\times 2)$ pour atteindre une valeur maximale à 5 jours qui est le double de celle mesurée dans le cortex adulte. Au cours de cette période, une évolution croissante de l'activité de la cytochrome $C$ oxydase a pu être observée et semble indiquer une maturation régulière des mitochondries depuis les derniers stades de la vie fœtale jusqu'au stade $10 \mathrm{j}$ p.p.

Le métabolisme rénal du palmitate peut être modifié chez le fotus de $20 \mathrm{j}$ post coïtum en imposant un jeûne sévère à la mère $(48 \mathrm{~h})$. Dans ces conditions on observe une augmentation d'activité de la P.C.T.1 $(\times 2)$ de même qu'une augmentation de l'oxydation du palmitate.

II est curieux de constater que l'activité de l'enzyme augmente dans les conditions où le taux plasmatique des acides gras libres augmente, c'est-à-dire à la naissance ou après un jeûne prolongé. Ces résultats suggèrent que l'augmentation d'activité de la P.C.T.1 observée à la naissance pourrait être non seulement liée à une maturation mitochondriale mais induite par l'augmentation des acides gras libres intervenant à ce moment. 


\section{References}

FREUND N., SEDRAOUI M., GELOSO J. P., 1984. Fatty acid oxidation by developing rat kidney. Biol. Neonate, 45, 183-187.

McGARRY J. D., LEATHERMAN G. F, FOSTER D. W., 1978. Carnitine palmitoy/transferase I; the site of inhibition of hepatic fatty acid oxidation by Malonyl-CoA J. biol. Chem. 253, 4128-4136. 